\title{
Characterization and Prognosis of Secondary Acute Myeloid Leukemia in an Asian Population: AML With Antecedent Hematological Disease Confers Worst Outcomes, Irrespective of Cytogenetic Risk
}

\author{
SHEEHYUN KIM ${ }^{1}$, SUNG-SOO YOON ${ }^{1,2,3}$, JUNSHIK HONG ${ }^{1,2,3}$,

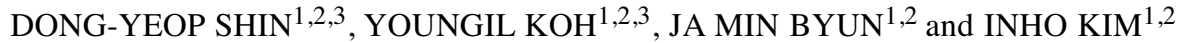 \\ ${ }^{1}$ Department of Internal Medicine, Seoul National University College of Medicine, \\ Seoul National University Hospital, Seoul, Republic of Korea; \\ ${ }^{2}$ Cancer Research Institute, Seoul National University College of Medicine, Seoul, Republic of Korea; \\ ${ }^{3}$ Center for Medical Innovation, Biomedical Research Institute, \\ Seoul National University Hospital, Seoul, Republic of Korea
}

\begin{abstract}
Background/Aim: Acute myeloid leukemia (AML) is a biologically heterogeneous disease that can be classified into de novo AML and secondary AML. Secondary AML can be further divided into therapy-related $A M L(t-A M L)$ or $A M L$ evolving from antecedent hematological disorder ( $A H D$ $A M L)$. This study evaluated the characteristics and prognosis of secondary AML in a homogeneous East Asian population who are often under-represented. Patients and Methods: This was a retrospective, longitudinal cohort study of Korean $A M L$ patients over 18 years old treated between January 2000 and December 2013. A total of 437 de novo AML (80.3\%), 41 t$A M L(7.5 \%)$, and 66 AHD-AML (12.1\%) were evaluated. Results: First, we found that secondary AML constituted about $19.7 \%$ of all AML cases, and $t-A M L$ was more prevalent than $A H D-A M L$. Second, we determined $A H D-A M L$ as a prognostic factor for inferior survival, independent of other risk factors (HR=2.137, 95\%CI=1.534-2.977, $p<0.001)$. The induction response rates correlated well with the overall survival. Furthermore, AHD-AML was associated
\end{abstract}

This article is freely accessible online.

Correspondence to: Ja Min Byun, MD, Ph.D., Department of Internal Medicine, Seoul National University Hospital, 101, Daehak-ro, Jongro-gu, Seoul 03080, Republic of Korea. Tel: +82 220721477, Fax: +82 27629662, e-mail: jaminbyun@naver.com or Inho Kim, MD, PhD, Department of Internal Medicine, Seoul National University Hospital, 101, Daehak-ro, Jongro-gu, Seoul 03080, Republic of Korea. Tel: +82 220720834, Fax: +82 27629662, e-mail: kim_dajung@hanmail.net

Key Words: Acute myeloid leukemia, secondary, therapy related, survival, mutations. with worst treatment outcomes and prognosis regardless of cytogenetic risk or age. Interestingly, $t$-AML was generally associated with better outcomes compared to AHD-AML despite the similarities in treatment schema. Conclusion: Secondary AML represents a broad spectrum of diseases and $t$-AML should be addressed separately from AHD-AML.

Acute myeloid leukemia (AML) is a biologically heterogeneous disease that can be classified into two distinct categories: 1) de novo AML that arises in the absence of an identified exposure or prodromal stem cell disorder; and 2) secondary AML. Secondary AML can be further divided into therapy-related AML ( $t$-AML) due to previous exposure to leukemogenic therapies including chemotherapy and radiotherapy, or, AML evolving from antecedent hematological disorder (AHD-AML) including myelodysplastic syndrome (MDS), myeloproliferative neoplasm (MPN), or aplastic anemia (AA) (1-3). Secondary AML is generally associated with poor clinical outcomes compared to de novo $\operatorname{AML}(4,5)$. However, there is still debate as to whether secondary AML itself is an independent risk factor, as secondary AML patients tend to be older and more fragile (6). Unfortunately, secondary AML patients are commonly excluded from clinical trials, limiting the understanding of the disease. Another unresolved issue is the discrepancies in response and survival rates of secondary AMLs: despite harboring a seemingly targetable mutation, JAK2, post-MPN AML is typically associated with abysmal prognosis, while selected t-AML patients show survivals similar to their de novo counterparts $(2,4)$. Despite continued attempts to genetically characterize secondary AML $(7,8)$, whether distinct somatic mutations underlie the different treatment responses remain largely unknown. As such, we carried out this study in an effort to refine the characteristics 


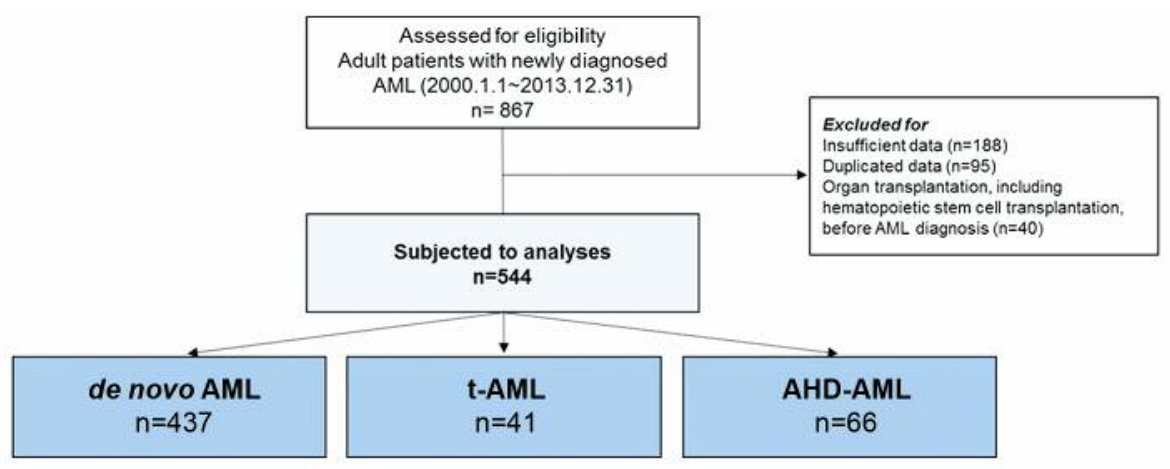

Figure 1. CONSORT diagram.

and prognosis of secondary AML patients, for whom there exist a critical unmet need of new therapeutic options. Specifically, we focused on a homogeneous East Asian population, which is often under-represented.

\section{Patients and Methods}

Study design and subjects. This was a retrospective, longitudinal cohort study of Korean AML patients over 18 years old treated between January 2000 and December 2013 at the Seoul National University Hospital. Initially, a total of 867 patients were identified (Figure 1). After excluding those with insufficient data, those who underwent organ transplantation including hematopoietic stem cell transplantation (HSCT) and duplicated data, 544 patients with complete set of bone marrow examination data and cytogenetic information were enrolled. In the end, there were 437 patients with de novo AML (80.3\%), 41 with t-AML (7.5\%), and 66 with AHD-AML (12.1\%). Their medical records were reviewed and analyzed for demographics and baseline disease characteristics including cytogenetics, chemotherapy dosing and schedule, factors related to HSCT, response to chemotherapy and HSCT, adverse events, and survival outcomes.

This study was conducted according to the Declaration of Helsinki and was approved by the institutional review board of Seoul National University Hospital (IRB No. H-1607-198-782). All authors had access to the study data and reviewed and approved this study.

AML diagnosis and risk stratification. The diagnosis of AML was made according to the WHO Classification of Hematopoietic Neoplasms, which requires identification of $20 \%$ or more leukemic blasts in the bone marrow (9). Cytogenetic studies were performed at each center, whose satisfactory performance was monitored by a national external quality assurance scheme. Bone marrow cells were cultured for $24 \mathrm{~h}$ and then the karyotype was analyzed using the standard G-banding technique. The karyotypes were constructed and chromosomal abnormalities were reported in accordance with the International System for Human Cytogenetic Nomenclature (10). Prognostic grouping of cytogenetics was performed according to Southwest Oncology Group (SWOG) criteria (11). Fms-related tyrosine kinase 3 (FLT3) internal tandem duplication (ITD) and nucleophosmin-1 (NPM1) mutations were analyzed using DNA samples obtained at initial diagnosis and multiplex polymerase chain reaction (PCR). Complex karyotype was defined as any karyotype with at least 3 chromosome aberrations, regardless of their type and the individual chromosomes involved. Monosomal karyotype was defined as 2 or more distinct autosomal chromosome monosomies or 1 single autosomal monosomy in addition to structural abnormalities.

Statistical analysis. The overall survival (OS) curves were estimated using the Kaplan-Meier method. OS was defined as the time from the date of AML diagnosis to death from any cause. If patients survived without death, the survival was censored on the last date of follow-up. Cox proportional hazards model and logistic regression were used to identify significant prognostic indicators for survival. Differences between groups were assessed using Student's t-test, one-way analysis of variance for continuous variables, or Pearson chi-square test for categorical variables, as appropriate. All data were analyzed using the Statistical Package for the Social Sciences software (IBM ${ }^{\circledR}$ SPSS ${ }^{\circledR}$ statistics, version 22.0, Armonk, NY, USA). $p$-Values of $<0.05$ was considered to be statistically significant.

\section{Results}

Patient characteristics. Table I represents the baseline characteristics of all patients. While sex distribution was uniform across different AML subtypes, patients with AHDAML tended to be older (median: 61.5, range=22-77 years) compared to patients with de novo AML (median: 51, range $=18-85$ years; $p=0.001$ ) and $\mathrm{t}-\mathrm{AML}$ (median: 53, range $=19-74$ years; $p=0.439$ ). Poor cytogenetics were most frequently observed in patients with AHD-AML (de novo AML $v s$. $\mathrm{t}-\mathrm{AML}, p=0.179$; de novo AML $v s$. AHD-AML, $p<0.001 ; \mathrm{t}-\mathrm{AML} v s$. AHD-AML, $p=0.321$ ).

Among t-AML patients, the most common diagnosis was lymphoma $(n=12,30 \%)$ and breast cancer $(n=7,17 \%)$, together constituting approximately half of the group (Figure 2A). The median latency between diagnosis of the primary disease and the diagnosis of AML was 47 months (range=31235 months).

As shown in Figure 2B, among AHD-AML patients, the most common diagnosis was MDS $(n=41,62 \%)$ followed by 
Table I. Patient characteristics.

\begin{tabular}{lccc}
\hline$\%$ & $\begin{array}{c}\text { de novo } \\
(\mathrm{N}=437)\end{array}$ & $\begin{array}{c}\mathrm{t}-\mathrm{AML} \\
(\mathrm{N}=41)\end{array}$ & $\begin{array}{c}\text { AHD-AML } \\
(\mathrm{N}=66)\end{array}$ \\
\hline Year of diagnosis & & & \\
$2000-2004$ & $82(18.8)$ & $9(22.0)$ & $16(24.2)$ \\
$2005-2009$ & $173(39.6)$ & $18(43.9)$ & $21(31.8)$ \\
$2010-2013$ & $182(41.6)$ & $14(34.1)$ & $29(43.9)$ \\
Age at dx (years) & & & \\
Median [range] & $51(18-85)$ & $53(19-74)$ & $61.5(22-77)$ \\
$<65$ years old & $345(78.9)$ & $27(65.9)$ & $42(63.6)$ \\
$\geq 65$ years old & $92(21.1)$ & $14(34.1)$ & $24(36.4)$ \\
Gender (male) & $261(59.7)$ & $21(51.2)$ & $38(57.6)$ \\
Cytogenetic risk group & & & \\
Favorable & $107(24.5)$ & $7(17.1)$ & 0 \\
Intermediate & $234(53.5)$ & $19(46.3)$ & $40(60.6)$ \\
Poor & $96(22.0)$ & $15(36.6)$ & $26(39.4)$ \\
Extramedullary involve & $37(8.5)$ & $6(14.6)$ & 0 \\
Lab findings at dx ${ }^{1}$ & & & \\
BM blast $(\%)$ & $57.1(27.5)$ & $56.1(27.4)$ & $37.4(20.4)$ \\
WBC count (103/1) & $31.4(83.7)$ & $27.4(50.0)$ & $13.8(20.9)$ \\
Platelet count (109/l) & $74.0(79.3)$ & $50.7(63.4)$ & $149.5(98.0)$ \\
Hb (g/dl) & $8.3(2.0)$ & $8.1(1.7)$ & $8.1(1.6)$ \\
Treatment & & & \\
Intensive chemotherapy & $424(97.0)$ & $36(87.8)$ & $56(84.8)$ \\
Low intensity chemotherapy 2 & $5(1.1)$ & $1(2.4)$ & $4(6.1)$ \\
No treatment & $8(1.4)$ & $4(9.8)$ & $6(9.1)$ \\
\hline & & & \\
\hline A & & & \\
& & &
\end{tabular}

t-AML: Therapy related AML; AHD: antecedent hematologic disease; dx: diagnosis; NA: not applicable; BM: bone marrow; WBC: white blood cell; Hb: hemoglobin. ${ }^{1}$ Values are presented as mean $( \pm$ standard deviation); ${ }^{2}$ Low intensity chemotherapy includes hypomethylating agents and low-dose cytarabine treatment.

MPN ( $\mathrm{n}=18,27 \%)$. When MDS-AML and MPN-AML were compared, there were no differences in the number of patients with poor cytogenetics (MDS-AML 39\% vs. MPN-AML $41.2 \%, p=0.879)$. Patients with AHD-AML were associated with significantly lower white blood cell (WBC) count at diagnosis compared with patients with de novo $\operatorname{AML}(p=0.001)$.

Treatment and response according to AML subtypes. In total, 516 out of 544 patients $(94.9 \%)$ underwent intensive chemotherapy (Table I). Per subtype, 97\% (424/437) of de novo AML patients were induced, while $87.8 \%$ (36/41) of tAML patients and $84.8 \%(56 / 66)$ of AHD-AML patients were induced. Patients with de novo AML were more likely to achieve complete remission (CR) than patients with other subtypes of AML, while patients with AHD-AML were least likely to achieve CR $(p<0.001$, Table II). Such lower CR rate for AHD-AML was observed across the cytogenetic risk groups. Only $19.6 \%$ of the AHD-AML patients were subsequently subjected to consolidation chemotherapy, while $68.2 \%$ of the de novo AML patients and $47.2 \%$ for the tAML patients received consolidation. With reference to age,
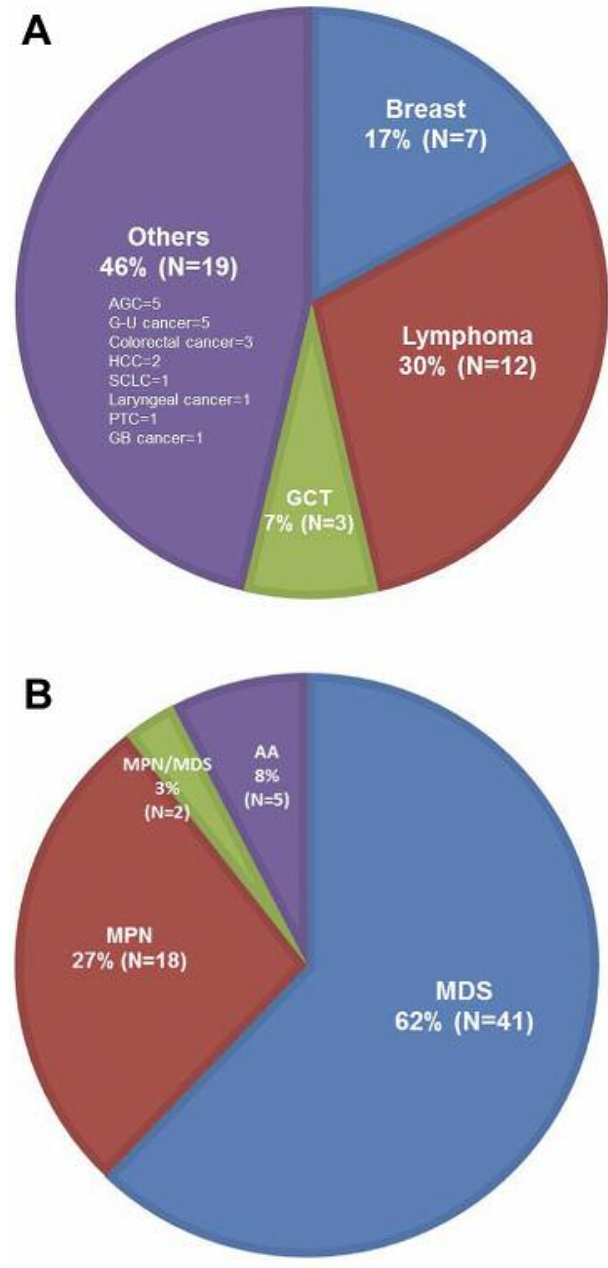

Figure 2. Subclassification of secondary AML. AML: Acute myeloid leukemia; MDS: myelodysplastic syndrome; MPN: myeloproliferative neoplasm; AA: aplastic anemia. (A) Therapy-related AML. (B) AML with antecedent hematological disease. (B) AML with antecedent hematological disease.

older patients showed trends towards lower CR rate in all 3 AML subtypes, however the difference was only significant in de novo AML $(86.3 \% \mathrm{CR}$ rate in patients $<65$ years old $v s .72 .0 \%$ in patients $\geq 65$ years old, $p=0.002$ ).

Death occurred most frequently in AHD-AML (Table II). Specifically, the majority of AHD-AML patients expired before $1^{\text {st }}$ relapse, suggesting high rates of treatment related mortality.

Overall survival. The median OS of all 544 patients was 20 months (Figure 3A), with improvement in survival evident per year of diagnosis. Overall, de novo AML patients were associated with best OS (median: 29 months) followed by tAML patients (median: 14 months) and AHD-AML patients 
Table II. Treatment schema and outcomes of patients undergoing intensive chemotherapy.

\begin{tabular}{|c|c|c|c|}
\hline$\%$ & $\begin{array}{l}\text { de novo } \\
(\mathrm{N}=424)\end{array}$ & $\begin{array}{l}t-A M L \\
(N=36)\end{array}$ & $\begin{array}{c}\text { AHD-AML } \\
(\mathrm{N}=56)\end{array}$ \\
\hline Induction CR & $354(89.4)$ & $24(66.7)$ & $18(32.1)$ \\
\hline \multicolumn{4}{|l|}{ Cytogenetic risk group } \\
\hline Favorable & $102 / 107(95.3)$ & $6 / 7(85.7)$ & NA \\
\hline Intermediate & $189 / 226(83.6)$ & $13 / 18(72.2)$ & $12 / 36$ \\
\hline Poor & $64 / 91(70.3)$ & $5 / 11(45.5)$ & $7 / 20(35.0)$ \\
\hline \multicolumn{4}{|l|}{ Age } \\
\hline$<65$ years old & $295 / 342(86.3)$ & $19 / 26(73.1)$ & $15 / 37(40.5)$ \\
\hline$\geq 65$ years old & $59 / 82(72.0)$ & $5 / 10(50.0)$ & $3 / 19(15.8)$ \\
\hline Consolidation chemotherapy & $289(68.2)$ & $17(47.2)$ & $11(19.6)$ \\
\hline Number (median, range) & $2(1-3)$ & $2(1-3)$ & $2(1-3)$ \\
\hline Upfront HSCT & $65(15.3)$ & $13(14.6)$ & $12(21.4)$ \\
\hline \multicolumn{4}{|l|}{ HSCT donor } \\
\hline Related/unrelated & $\begin{array}{l}43(66.2) / \\
22(33.8)\end{array}$ & $\begin{array}{c}10(76.9) / \\
3(23.1)\end{array}$ & $\begin{array}{l}5(41.7) / \\
7(58.3)\end{array}$ \\
\hline Match/mismatch & $\begin{array}{c}50(76.9) / \\
15(23.1)\end{array}$ & $\begin{array}{l}8(61.5) / \\
5(38.5)\end{array}$ & $\begin{array}{l}9(75.0) / \\
3(25.0)\end{array}$ \\
\hline \multicolumn{4}{|l|}{ HSCT conditioning } \\
\hline Reduced intensity & $45(69.2)$ & $10(76.9)$ & $8(66.7)$ \\
\hline Myeloablative & $20(30.8)$ & $3(23.1)$ & $4(33.3)$ \\
\hline \multicolumn{4}{|l|}{ Death } \\
\hline Any cause of death & $232(54.7)$ & $23(63.9)$ & $44(78.6)$ \\
\hline Death before $1^{\text {st }}$ relapse 1 & $68(29.3)$ & $8(34.8)$ & $24(54.5)$ \\
\hline Related to induction & 40 & 6 & 16 \\
\hline Related to consolidation & 11 & 0 & 1 \\
\hline Related to upfront HSCT & 17 & 2 & 7 \\
\hline
\end{tabular}

t-AML: Therapy related AML; AHD: antecedent hematologic disease; CR: complete remission; NA: not applicable; consol: consolidation HSCT: hematopoietic stem cell transplantation. ${ }^{1}$ Percentage out of total death.

(median: 7 months, Figure 3B). The difference in survival between de novo AML and t-AML did not reach statistical significance, but there was significant difference between de novo AML vs. AHD-AML $(p<0.001)$ and t-AML $v s$. AHDAML $(p=0.018)$. When MDS-AML (median OS: 7 months) and MPN-AML (median OS: 6 months) were compared, there was no difference in OS ( $p=0.349$, data not shown). Figure $3 \mathrm{C}$ shows the $\mathrm{OS}$ of patients per cytogenetic risk group. AHD-AML patients were associated with worst OS outcomes, irrespective of cytogenetic risk group.

When age was taken into consideration (Figure 4), patients $\geq 65$ years old (median OS: 12 months) were generally associated with poorer outcomes compared to patients $<65$ years old (median OS: 31 months, $p<0.001$ ). AHD-AML was associated with worst outcomes, irrespective of age (Figure $4 \mathrm{~A})$. In patients $<65$ years old, AHD-AML showed inferior survival compared to de novo AML in each of the 3 cytogenetic risk groups (Figure 4B), indicating that poor
Table III. Multivariable analysis for survival in patients undergoing intensive chemotherapy.

\begin{tabular}{lcc}
\hline & \multicolumn{2}{c}{ Overall survival } \\
\cline { 2 - 3 } & HR $(95 \% \mathrm{CI})$ & $p$-Value \\
\hline Age & $1.766(1.360-2.295)$ & $<0.001$ \\
$\quad$ 265 vs. $<65$ & $1.350(1.065-1.712)$ & 0.013 \\
Gender & ref & ref \\
$\quad$ Male vs. Female & $1.347(0.871-2.083)$ & 0.180 \\
Type of AML & $2.137(1.534-2.977)$ & $<0.001$ \\
de novo & ref & ref \\
t-AML & $0.839(0.627-1.122)$ & 0.236 \\
AHD-AML & Ref & 0.006 \\
Year of diagnosis & ref \\
2000-2004 & $1.743(1.248-2.434)$ & 0.001 \\
2005-2009 & $2.610(1.796-3.792)$ & $<0.001$ \\
2010-2013 & & \\
Cytogenetic risk group & & \\
Favorable & & \\
Intermediate & & \\
Poor & &
\end{tabular}

outcomes in AHD-AML depend on karyotype. In patients $\geq 65$ years old, while AHD-AML showed inferior survival to de novo AML $(p=0.034)$ in the intermediate risk group, there were no differences in survival between the 3 AML subtypes in the high-risk group (Figure 4C). There were only 8 patients with favorable cytogenetic risk ( 7 de novo AML, $1 \mathrm{t}$-AML), thus survival analysis was not performed.

In multivariate analyses (Table III), AHD-AML was recognized as independent prognostic factor for survival $(\mathrm{HR}=2.137,95 \% \mathrm{CI}=1.534-2.977, p<0.001)$, while $\mathrm{t}-\mathrm{AML}$ was not $(p=0.180)$. Other prognostic factors included older age, male sex and intermediate/poor cytogenetic risk.

\section{Discussion}

Secondary AML is generating substantial economic and social burdens as the number of cancer survivors is rapidly increasing (12). Recognizing the relative paucity of data from Asian populations, we carried out this study to investigate the characteristics and prognosis of secondary AML hoping of establishing ground works for more innovative therapeutic approaches for this often-neglected population of patients. First of all, through our study, we found that secondary AML constituted about $19.7 \%$ of all AML cases. Second, we determined AHD-AML as a prognostic factor for inferior survival, independent of other risk factors. AHD-AML was associated with worst treatment outcomes and prognosis regardless of cytogenetic risk or age. Interestingly, t-AML was generally associated with better outcomes compared to AHD-AML despite the similarities in treatment schema. 

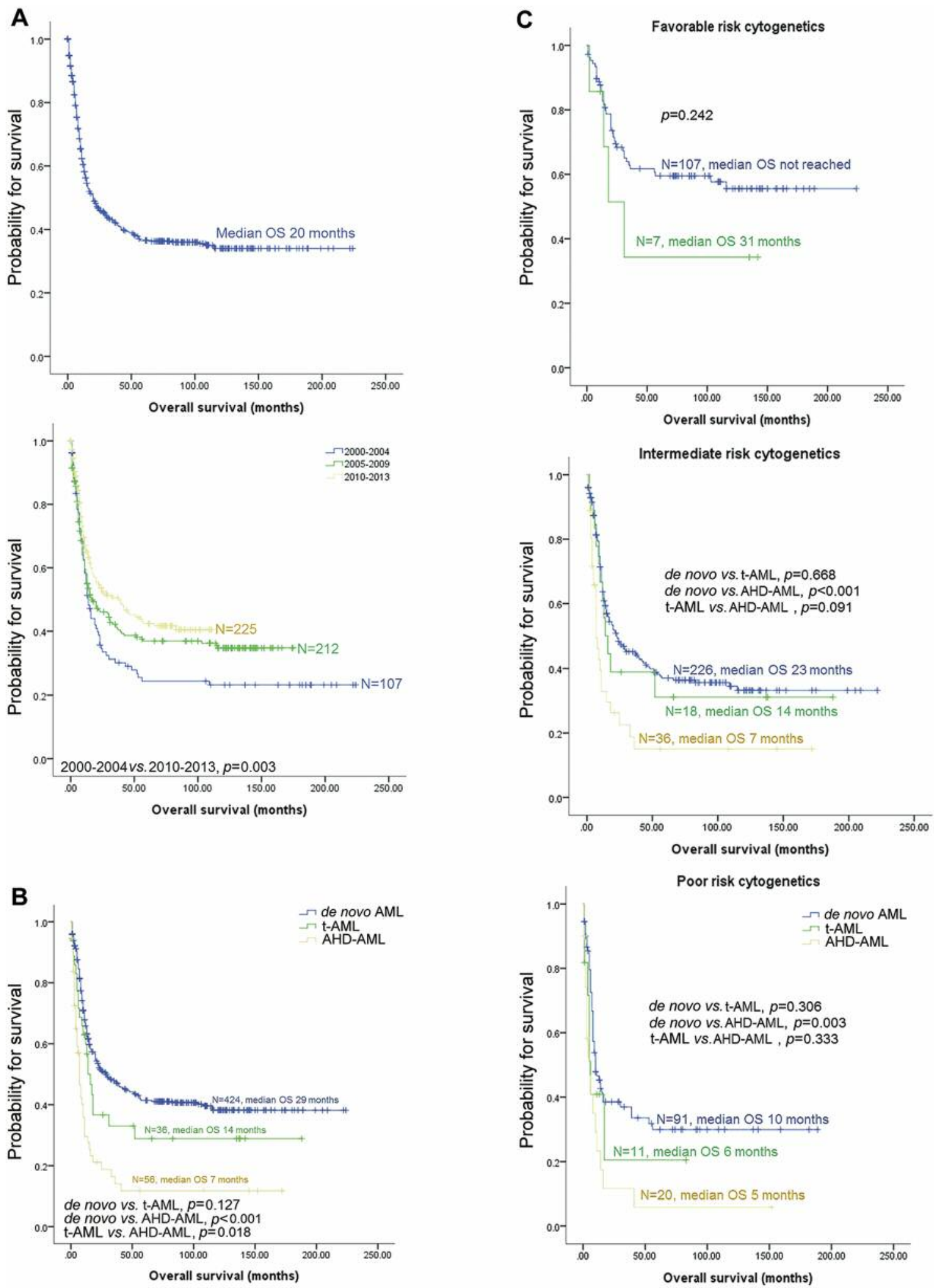

Figure 3. Overall survival according to year of diagnosis, AML subtypes and cytogenetic risk group. AML: Acute myeloid leukemia; -AML: therapy related AML; AHD-AML: AML with antecedent hematological disease. (A) Left, all patients; Right, according to year of diagnosis. (B) According to AML subtypes, for patients undergoing intensive chemotherapy. (C) According to cytogenetic risks groups, for patients undergoing intensive chemotherapy. Left, favorable risk group; Middle, intermediate risk group; Right, poor risk group. 

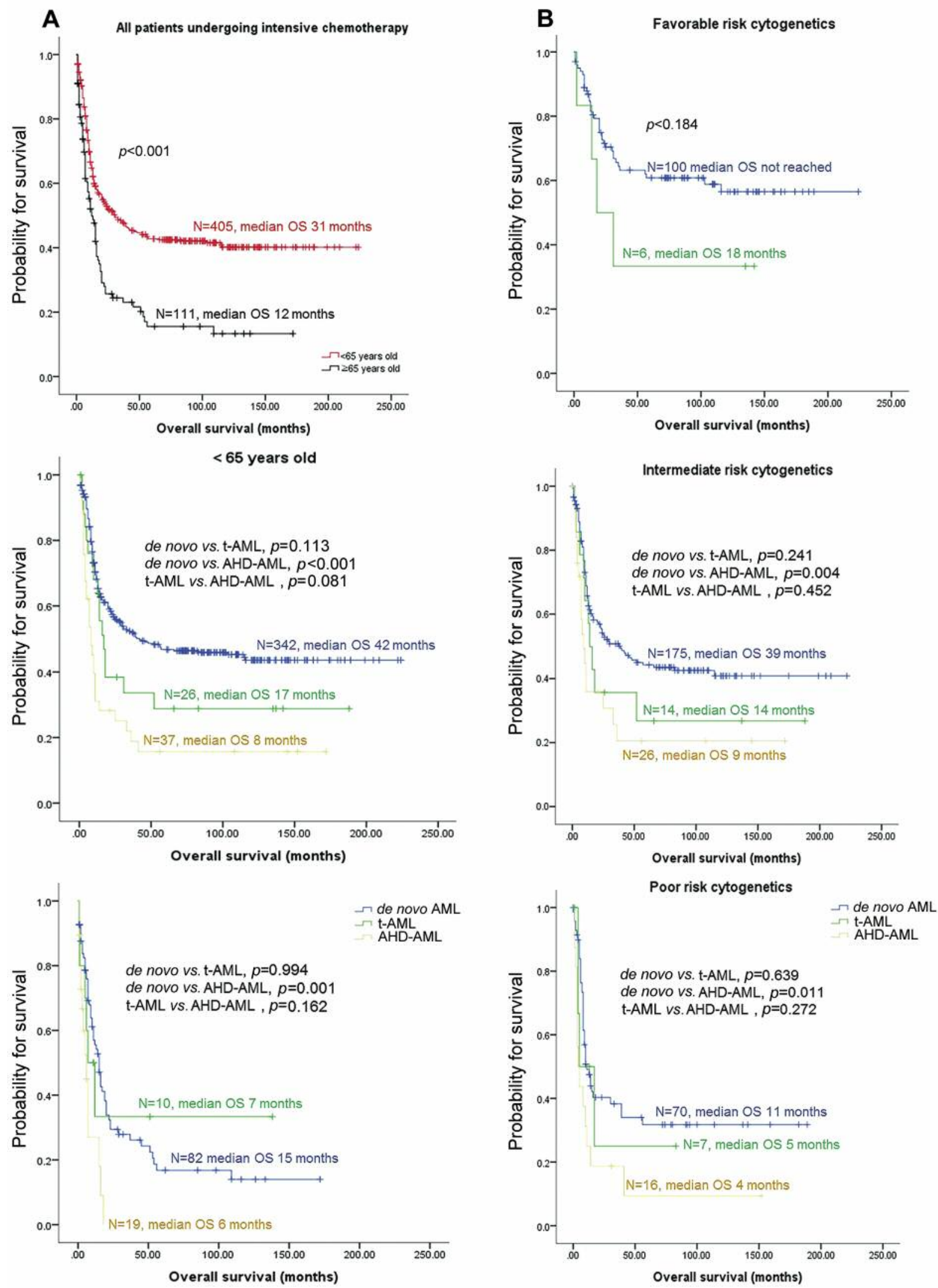

Figure 4. Continued 

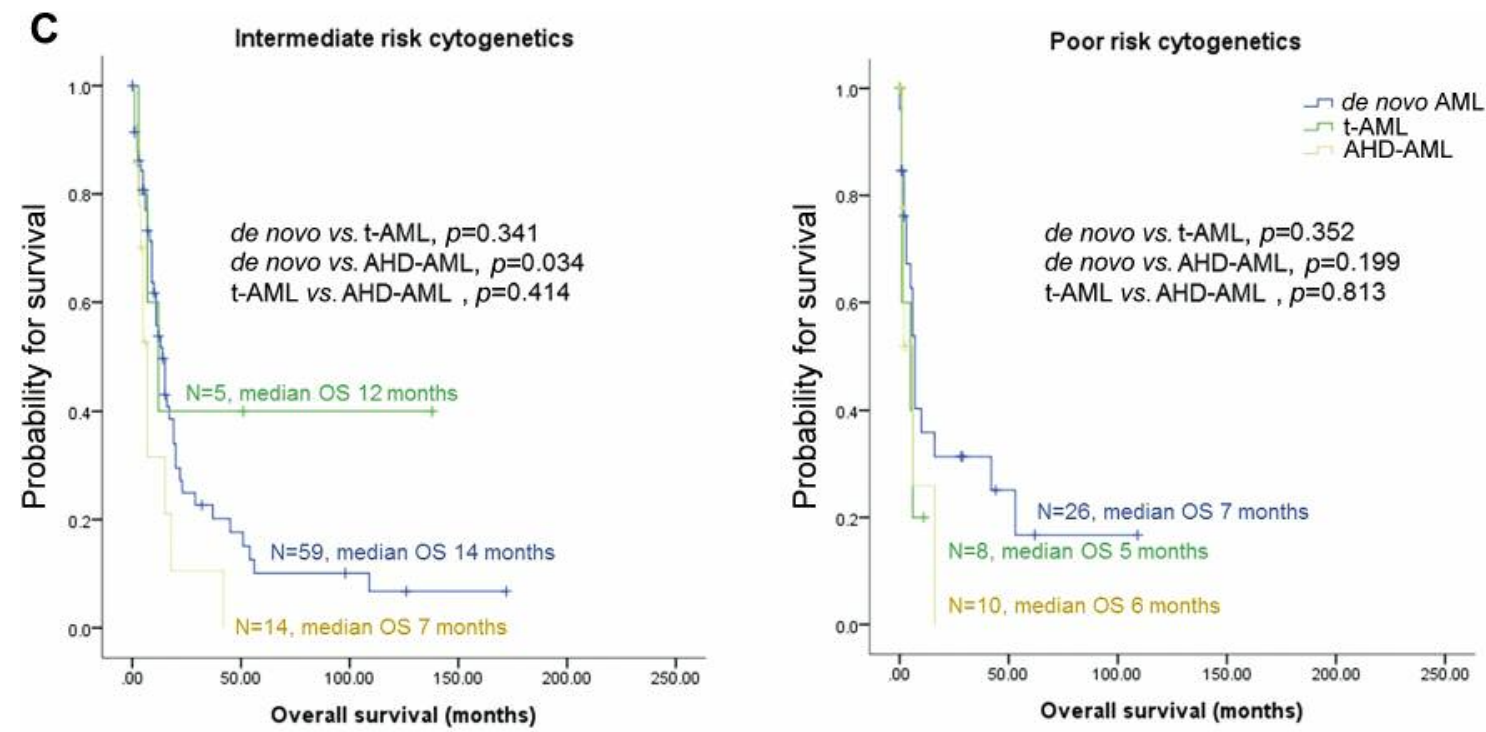

Figure 4. Overall survival according age. AML, acute myeloid leukemia; $t$-AML, therapy related AML; AHD-AML, AML with antecedent hematological disease. (A) According to age group, for patients undergoing intensive chemotherapy. Left, all patients; Middle, patients $<65$ years old; Right, patients $\geq 65$ years old. (B) Patients <65 years old undergoing intensive chemotherapy. Left, favorable risk group; Middle, intermediate risk group; Right, poor risk group. (C) Patients $\geq 65$ years old undergoing intensive chemotherapy. Left, intermediate risk group; Right, poor risk group.

As in previous reports $(2,13)$, lymphoma was the most common primary malignancy followed by breast cancer in tAML group. The survival correlated with response rates. Higher induction $\mathrm{CR}$ rate was observed in de novo $\mathrm{AML}$ across all cytogenetic risk groups, followed by t-AML and AHD-AML. The difference in induction CR rates translated into difference in the number of patients undergoing consolidation treatment. Notably, the number of consolidation cycles and percentage of patients receiving upfront HSCT were similar between the 3 groups. Based on our data and Nilsson et al.'s report (14), we suggest that upfront HSCT is the only realistic curative option for patients with AHD-AML. However, since treatment related mortality was highest in AHD-AML, careful selection of patients and adaptive modifications during HSCT process is crucial. Also, this observation suggests more innovative therapeutic approaches are needed for AHD-AML patients.

One of the most obvious limitations of this study is the lack of detailed genetic sequencing data. Since the study period was set between year 2000 and 2013, genetic sequencing data was not available in most patients. Whole genome sequencing data was available in 140 patients ( 112 de novo AML, 9 t-AML, 19 AHD-AML) but sequencing was performed at different time points using various platforms, and since the quality of sequencing could not be guaranteed, comparative analyses were not performed. As specific mutations can distinguish sAML like disease within t-AML and elderly de novo $\operatorname{AML}(7,15,16)$, a follow up study with detailed genetic data is needed for better classification of Asian sAML. Another pitfall is the small number of patients. Although the number of patients enrolled in this study is not small by any means for a single center, it is not big enough to be readily extrapolated as national data. However, being a single center data, there is the advantage of uniformity (i.e. patients received same sequence of diagnostics and treatment) which assures the quality of our data. Nevertheless, a larger epidemiologic study, preferably of East Asian descents, should ensue for corroboration of our findings.

In conclusion, we provide a better understanding of AML landscape in the Korean population. Since secondary AML is a rather heterogenous disease, t-AML should be addressed separately from AHD-AML. Continuous efforts to better characterize and treat secondary AML are crucial.

\section{Conflicts of Interest}

No conflicts of interest to disclose regarding this study.

\section{Authors' Contributions}

Designed the study: Ja Min Byun, Junshik Hong. Patient enrollment and data collection: all the authors. Analyzed the data: Ja Min Byun, Sheehyun Kim. Wrote the paper: Ja Min Byun, Sheehyun Kim. Revised the paper: all the authors.

\section{Acknowledgements}

A part of this study's results has been presented as a poster at the $24^{\text {th }}$ Annual Congress of Asia-Pacific Blood and Marrow Transplantation group, 2019, Busan, Republic of Korea. 


\section{References}

1 Patel JP, Gonen M, Figueroa ME, Fernandez H, Sun Z, Racevskis J, Van Vlierberghe P, Dolgalev I, Thomas S, Aminova O, Huberman K, Cheng J, Viale A, Socci ND, Heguy A, Cherry A, Vance G, Higgins RR, Ketterling RP, Gallagher RE, Litzow M, van den Brink MR, Lazarus HM, Rowe JM, Luger S, Ferrando A, Paietta E, Tallman MS, Melnick A, Abdel-Wahab O and Levine RL: Prognostic relevance of integrated genetic profiling in acute myeloid leukemia. N Engl J Med 366(12): 1079-1089, 2012. PMID: 22417203. DOI: 10.1056/NEJMoa1112304

2 Granfeldt Ostgard LS, Medeiros BC, Sengelov H, Norgaard M, Andersen MK, Dufva IH, Friis LS, Kjeldsen E, Marcher CW, Preiss B, Severinsen $M$ and Norgaard JM: Epidemiology and clinical significance of secondary and therapy-related acute myeloid leukemia: A national population-based cohort study. J Clin Oncol 33(31): 3641-3649, 2015. PMID: 26304885. DOI: 10.1200/JCO.2014.60.0890

3 Arber DA, Orazi A, Hasserjian R, Thiele J, Borowitz MJ, Le Beau MM, Bloomfield CD, Cazzola M and Vardiman JW: The 2016 revision to the world health organization classification of myeloid neoplasms and acute leukemia. Blood 127(20): 2391-2405, 2016. PMID: 31659364. DOI: 10.1182/blood-2016-06-721662

4 Hulegardh E, Nilsson C, Lazarevic V, Garelius H, Antunovic P, Rangert Derolf A, Mollgard L, Uggla B, Wennstrom L, Wahlin A, Hoglund M, Juliusson G, Stockelberg D and Lehmann S: Characterization and prognostic features of secondary acute myeloid leukemia in a population-based setting: A report from the swedish acute leukemia registry. Am J Hematol 90(3): 208214, 2015. PMID: 25421221. DOI: 10.1002/ajh.23908

5 Kayser S, Dohner K, Krauter J, Kohne CH, Horst HA, Held G, von Lilienfeld-Toal M, Wilhelm S, Kundgen A, Gotze K, Rummel M, Nachbaur D, Schlegelberger B, Gohring G, Spath D, Morlok C, Zucknick M, Ganser A, Dohner H, Schlenk RF and German-Austrian A: The impact of therapy-related acute myeloid leukemia (aml) on outcome in 2853 adult patients with newly diagnosed AML. Blood 117(7): 2137-2145, 2011. PMID: 21127174. DOI: 10.1182/blood-2010-08-301713

6 Stolzel F, Pfirrmann M, Aulitzky WE, Kaufmann M, Bodenstein H, Bornhauser M, Rollig C, Kramer M, Mohr B, Oelschlagel U, Schmitz N, Soucek S, Thiede C, Ehninger G, Schaich M and Study Alliance L: Risk stratification using a new prognostic score for patients with secondary acute myeloid leukemia: Results of the prospective AML96 trial. Leukemia 25(3): 420428, 2011. PMID: 21135859. DOI: 10.1038/leu.2010.279

7 Lindsley RC, Mar BG, Mazzola E, Grauman PV, Shareef S, Allen SL, Pigneux A, Wetzler M, Stuart RK, Erba HP, Damon LE, Powell BL, Lindeman N, Steensma DP, Wadleigh M, DeAngelo DJ, Neuberg D, Stone RM and Ebert BL: Acute myeloid leukemia ontogeny is defined by distinct somatic mutations. Blood 125(9): 1367-1376, 2015. PMID: 25550361. DOI: $10.1182 /$ blood-2014-11-610543

8 Walter MJ, Shen D, Ding L, Shao J, Koboldt DC, Chen K, Larson DE, McLellan MD, Dooling D, Abbott R, Fulton R, Magrini V, Schmidt H, Kalicki-Veizer J, O'Laughlin M, Fan X, Grillot M, Witowski S, Heath S, Frater JL, Eades W, Tomasson M, Westervelt P, DiPersio JF, Link DC, Mardis ER, Ley TJ, Wilson RK and Graubert TA: Clonal architecture of secondary acute myeloid leukemia. N Engl J Med 366(12): 1090-1098, 2012. PMID: 22417201. DOI: 10.1056/NEJMoa1106968
9 Vardiman JW, Thiele J, Arber DA, Brunning RD, Borowitz MJ, Porwit A, Harris NL, Le Beau MM, Hellstrom-Lindberg E, Tefferi A and Bloomfield CD: The 2008 revision of the world health organization (who) classification of myeloid neoplasms and acute leukemia: Rationale and important changes. Blood 114(5): 937-951, 2009. PMID: 19357394. DOI: 10.1182/blood2009-03-209262

10 Simons A, Shaffer LG and Hastings RJ: Cytogenetic nomenclature: Changes in the iscn 2013 compared to the 2009 edition. Cytogenet Genome Res 141(1): 1-6, 2013. PMID: 23817294. DOI: $10.1159 / 000353118$

11 Slovak ML, Kopecky KJ, Cassileth PA, Harrington DH, Theil KS, Mohamed A, Paietta E, Willman CL, Head DR, Rowe JM, Forman SJ and Appelbaum FR: Karyotypic analysis predicts outcome of preremission and postremission therapy in adult acute myeloid leukemia: A southwest oncology group/eastern cooperative oncology group study. Blood 96(13): 4075-4083, 2000. PMID: 11110676.

12 Morton LM, Dores GM, Tucker MA, Kim CJ, Onel K, Gilbert ES, Fraumeni JF, Jr. and Curtis RE: Evolving risk of therapyrelated acute myeloid leukemia following cancer chemotherapy among adults in the united states, 1975-2008. Blood 121(15): 2996-3004, 2013. PMID: 23412096. DOI: 10.1182/blood-201208-448068

13 Sasaki K, Jabbour E, Cortes J, Kadia T, Garcia-Manero G, Borthakur G, Jain P, Pierce S, Daver N, Takahashi K, O'Brien S, Kantarjian H and Ravandi F: Outcome of patients with therapy-related acute myeloid leukemia with or without a history of myelodysplasia. Clin Lymphoma Myeloma Leuk 16(11): 616624, 2016. PMID: 27601000. DOI: 10.1016/j.clml.2016.08.015

14 Nilsson C, Hulegardh E, Garelius H, Mollgard L, Brune M, Wahlin A, Lenhoff S, Frodin U, Remberger M, Hoglund M, Juliusson G, Stockelberg D and Lehmann S: Secondary acute myeloid leukemia and the role of allogeneic stem cell transplantation in a population-based setting. Biol Blood Marrow Transplant 25(9): 1770-1778, 2019. PMID: 31176789. DOI: 10.1016/j.bbmt.2019.05.038

15 Boddu PC, Kantarjian HM, Ravandi F, Garcia-Manero G, Verstovsek S, Jabbour EJ, Takahashi K, Bhalla K, Konopleva M, DiNardo CD, Ohanian M, Pemmaraju N, Jain N, Pierce S, Wierda WG, Cortes JE and Kadia TM: Characteristics and outcomes of older patients with secondary acute myeloid leukemia according to treatment approach. Cancer 123(16): 3050-3060, 2017. PMID: 28387922. DOI: 10.1002/cncr.30704

16 Boddu P, Kantarjian HM, Garcia-Manero G, Ravandi F, Verstovsek S, Jabbour E, Borthakur G, Konopleva M, Bhalla KN, Daver N, DiNardo CD, Benton CB, Takahashi K, Estrov Z, Pierce SR, Andreeff M, Cortes JE and Kadia TM: Treated secondary acute myeloid leukemia: A distinct high-risk subset of aml with adverse prognosis. Blood Adv 1(17): 1312-1323, 2017. PMID: 29296774. DOI: 10.1182/bloodadvances.2017008227

Received March 3, 2020

Revised March 17, 2020

Accepted March 19, 2020 